\title{
BMJ Open Development of a home-visit nursing scale for helping spousal caregivers of terminal cancer patients develop positive perspectives of their caregiving experiences: a cross-sectional study
}

Mari Karikawa (D) , ${ }^{1}$ Hisae Nakatani ${ }^{2}$

To cite: Karikawa M,

Nakatani H. Development of a home-visit nursing scale for helping spousal caregivers of terminal cancer patients develop positive perspectives of their caregiving experiences: a crosssectional study. BMJ Open 2019;9:e031057. doi:10.1136/ bmjopen-2019-031057

- Prepublication history and additional material for this paper are available online. To view these files, please visit the journal online (http://dx.doi. org/10.1136/bmjopen-2019031057).

Received 13 April 2019 Revised 08 November 2019 Accepted 21 November 2019

Check for updates

(C) Author(s) (or their employer(s)) 2019. Re-use permitted under CC BY-NC. No commercial re-use. See rights and permissions. Published by BMJ.

${ }^{1}$ Graduate School of Biomedical \& Health Sciences, Hiroshima University, Hiroshima, Japan

${ }^{2}$ Graduate School of Biomedical \& Health Sciences, Division of Nursing Science, Hiroshima University, Hiroshima, Japan

Correspondence to

Ms Mari Karikawa;

mari.karikawa@gmail.com

\section{ABSTRACT}

Objective Home-visit nurses play a key role in supporting the spouses of terminal cancer patients and encouraging positive perspectives of the caregiving experience. This study aimed to develop a scale to support nurses in self-assessing their practice around this important role.

Design Cross-sectional questionnaire study. Setting The Home Nursing Scale to Help Spousal Caregivers (HNS-HSC) questionnaire for self-assessment of home-visit nursing to spouses was developed based on interviews with spouses and literature reviews.

Participants Overall, 1500 home-visit nurses nationwide who had experience in supporting spousal caregivers and their patients in the predeath and postdeath periods were approached for participation.

Main outcome measure Planned exploratory and confirmatory factor analyses were used to assess the underlying dimensions of the HNS-HSC; Cronbach's $\alpha$ was used to determine the reliability. The Japanese version of Frommelt Attitude Toward Care of the Dying Scale Form B (FAT-COD-B-J) and Grief Care scale were administered to assess convergent and discriminant validity.

Results Exploratory and confirmatory factor analyses identified 26 items on five factors: 'helping spouses plan their futures' 'helping caregivers alleviate any regrets regarding their care', 'understanding the bond between a couple', 'providing support for anticipatory grief', and 'addressing spousal caregivers' emotions after their spouses' deaths'. The final model showed acceptable goodness-of-fit indices. The Cronbach's $\alpha$ for the entire scale was 0.949 and exceeded 0.822 for each factor. The correlation coefficient with the FAT-COD-B-J, which served as an external validation, was 0.35 . The correlation coefficients for the three grief care scales were $0.64,0.45$ and 0.72 , respectively.

Conclusions This scale is a reliable and valid tool for visiting nurses to self-assess their knowledge, skills and practice around helping spousal caregivers. By using this scale, it is expected to change nursing practice in pursuit of improving quality of life of spouses.
Strengths and limitations of this study

- This is the first quantitative study for selfassessment of visiting nurses' practices for terminal cancer patients' spousal caregivers.

- This scale was tested with a total sample of 1500 visiting nurses practicing Japanese palliative care.

- We examined the reliability and validity of a questionnaire providing a quantitative method for nurses to self-evaluate assisting spousal caregivers of terminal cancer patients to adopt positive perspectives of their caregiving experiences.

- Scale items were selected from a limited number of survivors and literature reviews, so they may not cover all cancer patients and their families; thus, it is necessary to use this scale carefully.

- This scale was tested only by visiting nurses providing palliative care in Japan, so further validation in other countries in the future is necessary.

\section{INTRODUCTION}

The population of Japan is ageing rapidly, and this is expected to lead to an increase in the number of cancer patients. ${ }^{1}$ Consequently, securing locations for such patients to recuperate is an urgent issue. In addition, $47 \%$ of Japanese citizens answered that they would like to be treated at home if they were diagnosed with terminal cancer. ${ }^{2}$ Based on these facts, the improvement of home palliative care services is indispensable for terminal cancer patients. Japan's Ministry of Health, Labour and Welfare $^{3}$ is promoting palliative care and end-of-life medical care in the home by creating incentives for home deaths through medical insurance and long-term care insurance. However, in Japan, the death rate at home for cancer patients is still as low as $11 \%,{ }^{4}$ and it is assumed that the support system for terminal cancer patients and their families at home is insufficient. 
Among families caring for end-stage cancer patients, $72 \%$ had a high risk of anxiety, and over $60 \%$ had a risk of distress and depression. ${ }^{5}$ Additionally, in a domestic study, $79 \%$ of such families experienced sleeplessness and $57 \%$ experienced a depressed mood. For this reason, it has been reported that family caregivers feel helpless and guilty because they have an inability to do anything for the patient and cannot accept the rapid deterioration of the patient's condition. ${ }^{6}$ It has also been reported that the high levels of pre-loss psychological distress is associated with high levels of postloss avoidance ${ }^{7}$ and complicated grief $^{89}$ in caregiving families of end-stage cancer patients. More than $50 \%$ of families of cancer patients who have received hospice home care have clinically significant depressive symptoms 1 year after bereavement. ${ }^{10}$ In particular, the death of a spouse has been reported to cause depressive symptoms. ${ }^{1112}$

Apart from these negative psychological states, the existence of positive psychological states has been suggested. In the West, bereaved coping strategies include 'continuous bonds', 13 14 'meaning,15 16 and 'emotional disclosure'. ${ }^{17}$ However, due to differences in bereavement-related religious/cultural factors in each country, there is no consensus on which coping strategies will contribute to the survivor's psychological state. In Japan, it is believed that the patient's soul lives forever and gives encouragement to the bereaved family. ${ }^{18}$ Examining family caregivers, it has become clear that $60 \%-70 \%$ of caregivers have a positive perception of the caregiving experience. ${ }^{19}{ }^{20}$ Lee $e t a l^{21}$ report that the caregiving effort for cancer patients and the experience of spending the last hours with the patient is important for the bereaved family caregiver. Some previous studies have shown that bereaved families who cared for cancer patients can address their grief by adopting a positive outlook of their experience regarding caregiving for their loved one up to their death. ${ }^{22-24}$ Thus, enhancing caregivers' positive feelings about the care they provide is an important element of grief support.

Several previous studies have examined the palliative care needs of family caregivers and home-care nurses, as well as the nursing practices and attitudes for effective palliative care. ${ }^{25-30}$ Home palliative care services in Japan provide a wide range of support, including symptom management, patient and family mental care, and coordination with family and people involved in care. $^{31}$ Additionally, bereavement care practiced by nurses is structured. ${ }^{29}$ However, in Japan, grief care after bereavement is not implemented properly because there is no institutional remuneration and the care is left up to each visiting nursing station. In fact, about $33 \%-49 \%$ of visiting nurses felt difficulty communicating with terminal patients and their families. ${ }^{32}$ This may be due to a lack of palliative care experience or expertise. Healthcare professionals also mentioned insufficient time and lack of knowledge of bereaved care. ${ }^{33}$ According to previous research, ${ }^{34}$ lack of personal achievement is pointed out as one of the factors associated with burnout. If visiting nurses practicing palliative care have difficulty supporting their patients and their families and are unable to cope with them, they seem more prone to develop burnout.

Therefore, the development of a scale for nurses to self-evaluate home-visit nursing that affirms the spousal caregiver is meaningful for both patients, their families and nurses. In this study, we aimed to develop and validate a home-visit nursing scale (the 'Home Nursing Scale to Help Spousal Caregivers' (HNS-HSC)) that can guide nurses in helping spousal caregivers of terminal cancer patients adopt positive perspectives of their caregiving experiences.

\section{METHODS}

The HNS-HSC was developed by: (1) creating an item pool, (2) evaluating the content and face validity to generate the initial scale, (3) sending the initial scale to a sample of home-visit nurses, (4) conducting item analysis on the questionnaire results, (5) conducting factor analyses, (6) determining the scale's reliability and (7) determining the scale's validity.

\section{Developing the initial scale}

We previously conducted interviews from August to November 2013 to explore the caregiving experience of 13 spouses whose patient had died at home in the previous 6-24 months. ${ }^{22}$ The interviews were conducted within this time frame after the bereavement to ensure that the most intense period of grief had passed and to allow the caregiver to reflect on the time of care. ${ }^{35} \mathrm{We}$ subsequently conducted a second, semi-structured interview with five spouses who had reported a positive view of their first caring experience 2 years after the first interview. The interviewer raised topics such as (1) what the research participants felt when providing care to the patient and (2) their awareness of the significance and value of that experience when reflecting on their home caregiving. We then performed qualitative content analysis using interview data, supervised by two researchers in regional and home nursing science. Particular focus was placed on elements of nursing support that could enhance spousal caregivers' positive feelings when providing caregiving. Based on the types of support we identified, as well as others identified through a literature review, ${ }^{36-46}$ we generated a scale of 115 items, which were classified into three time periods: from the beginning of home care to the end of the patient's stable condition, the dying period, and the postdeath period.

The content and face validity of the 115 items were then checked by six home hospice care experts and two researchers in home nursing.

The content and face validity of the 115-item pool were confirmed by six home hospice care experts for the purpose of selecting questions, and similar items were summarised. At that time, items judged inappropriate by more than two experts, items spanning multiple factors, and items that were ambiguous in terms of expression 
were corrected or deleted. Afterward, we heard opinions from two home nursing researchers for the purpose of examining content validity. Following this process, we preliminarily selected 38 items across nine domains to comprise the initial HNS-HSC. This process is displayed in online supplementary appendix 1 . The nine domains across the three time periods were as follows.

1. Support for home care while the patient is in stable condition:

1)Support in daily life, based on a consciousness that the couple's time together is ending.

2) Promotion of nursing care that includes family members.

3) Support of end-of-life decision-making.

4) Support for promoting positive emotions concerning patient's caregiving.

5) Providing information regarding signs that the patient's death is near.

2. Support for the dying period:

1) Support during the dying period to help ensure the patient has a peaceful death.

3. Support for the postdeath period:

1) Listening to the bereaved caregiver's expression of feelings and perceptions regarding experiencing the death.

2) Helping the bereaved caregiver develop relationships with other people.

3) Helping the bereaved caregiver plan his/her future.

\section{Validating the initial HNS-HSC}

The initial 38-item HNS-HSC was sent to a sample of home-visit nurses across Japan as part of a questionnaire.

\section{Participants}

The number of nurses used to validate this tool was calculated based on an item to participant ratio of 1:5 to $1: 10{ }^{4748}$ The sample size was determined with reference to the collection rate of mail surveys for visiting nurses in Japan. ${ }^{49}$ We targeted 1500 home-visit nurses from 500 randomly selected visiting-nursing stations, which were randomly selected from the 7189 stations listed in the nursing care insurance system information database. All stations supported 24 hours visits, care for severely ill patients, and at-home death. All targeted nurses had experience in providing predeath and postdeath nursing support for spousal caregivers of terminal cancer patients who died at home.

\section{Procedure}

We sent a research request letter and copies of the questionnaire to the manager of each of the 500 selected nursing stations, asking them to distribute the questionnaire to three of the station's visiting nurses who satisfied the criteria. We asked the nurses to voluntarily answer the questionnaire and then mail it to the researchers. The survey was conducted between March and September 2018.

\begin{tabular}{|c|c|c|c|}
\hline Characteristics & & $\mathbf{N}$ & $\%$ \\
\hline \multirow[t]{2}{*}{ Gender } & Female & 436 & 96.2 \\
\hline & Male & 17 & 3.8 \\
\hline Age & $46.57(8.29)^{*}$ & & \\
\hline \multirow[t]{5}{*}{ Position } & Staff nurse & 285 & 62.9 \\
\hline & Chief & 37 & 8.2 \\
\hline & Administrator & 122 & 26.9 \\
\hline & Other & 6 & 1.3 \\
\hline & Missing data & 3 & 0.7 \\
\hline \multirow{5}{*}{$\begin{array}{l}\text { Number of years of } \\
\text { experience as home- } \\
\text { visit nurse }\end{array}$} & $1-5$ & 186 & 41.1 \\
\hline & $6-10$ & 103 & 22.7 \\
\hline & $11-15$ & 74 & 16.3 \\
\hline & $16-20$ & 60 & 13.2 \\
\hline & $>20$ & 30 & 6.6 \\
\hline \multirow{5}{*}{$\begin{array}{l}\text { Number of cases } \\
\text { involving home } \\
\text { hospice care }\end{array}$} & $1-2$ & 37 & 8.2 \\
\hline & $3-5$ & 75 & 16.6 \\
\hline & $6-9$ & 62 & 13.7 \\
\hline & $>9$ & 271 & 59.8 \\
\hline & Missing data & 8 & 1.7 \\
\hline \multirow{5}{*}{$\begin{array}{l}\text { Number of visits after } \\
\text { the patient's death }\end{array}$} & Once & 309 & 68.2 \\
\hline & 2-3 times & 58 & 12.8 \\
\hline & $>3$ & 21 & 4.6 \\
\hline & Others & 12 & 2.6 \\
\hline & Missing data & 53 & 11.7 \\
\hline \multirow{5}{*}{$\begin{array}{l}\text { Visiting time after } \\
\text { patient's death } \\
\text { (multiple answers } \\
\text { possible) }\end{array}$} & $<2$ weeks & 115 & 25.4 \\
\hline & $\begin{array}{l}2 \text { weeks to less } \\
\text { than } 1 \text { month }\end{array}$ & 236 & 52.1 \\
\hline & $\begin{array}{l}\text { One month to less } \\
\text { than } 6 \text { months }\end{array}$ & 158 & 34.9 \\
\hline & $\begin{array}{l}6 \text { months to less } \\
\text { than } 12 \text { months }\end{array}$ & 18 & 4 \\
\hline & $>12$ months & 13 & 2.9 \\
\hline \multirow{2}{*}{$\begin{array}{l}\text { Learning experiences } \\
\text { of home-based } \\
\text { palliative care }\end{array}$} & Yes & 391 & 86.3 \\
\hline & No & 62 & 13.7 \\
\hline \multirow{4}{*}{$\begin{array}{l}\text { Degree of motivation } \\
\text { for home-based } \\
\text { palliative care }\end{array}$} & Yes & 379 & 83.7 \\
\hline & A little & 65 & 14.3 \\
\hline & Not much & 5 & 1.1 \\
\hline & No & 4 & 0.9 \\
\hline
\end{tabular}

*Mean (SD).

\section{Measures}

The basic data investigated in the questionnaire on participant's attributes and visiting care-related variables are shown in table 1 . We then asked participants to rate how often they practiced each of the 38 items in the initial HNS-HSC by using a Likert-type scale ranging from 1 ('I do not practice at all') to 5 ('I definitely practice'). Additionally, (1) the Japanese version of the 
Frommelt Attitude Toward Care of the Dying Scale Form B (FATCOD- B-J), ${ }^{51}$ (2) the grief care from the beginning of home care to the terminal period (GCBT), (3) the grief care at the patient's deathbed (GCDB), and (4) the grief care after the patient's death $(G C A D)^{29}$ were used. These scales are displayed in online supplementary appendix 2. The FATCOD- B-J is based on Frommelt's original FATCOD, ${ }^{26}{ }^{27}$ having been translated into Japanese and validated by Nakai et al. ${ }^{51}$ Following established conventions, ${ }^{51}$ we presented two factors from the FATCOD- B-J : 'positive attitude towards caring for the dying patient', and 'perceptions of patient- and familycentered care'. Cronbach's $\alpha$ coefficient on this scale was 0.85 . The Grief Care Provided by Nurses comprises three scales: (1) GCBT, (2) GCDB and (3) GCAD. ${ }^{29}$ The GCBT scale has three subscales: (1) promotion of acceptance of death and explanation of the death attendance system, (2) support of continuation of the family's care with respect to their intent, and (3) sympathy for the family's feelings. The GCDB scale contains one factor with five items. The GCAD scale has three subscales: (1) sharing and support of the family's experience of the patient's death, (2) psychosocial support for rebuilding life, and (3) grasping of state for resuming social activities. The Cronbach's $\alpha$ coefficient of each scale was $0.93,0.66$ and 0.93, respectively. Although the Cronbach's $\alpha$ coefficient of GCDB was low, the number of items of this scale was five. If the number of items is less than 10 items, Cronbach's $\alpha>0.50$ is considered acceptable ${ }^{52}$ indicating internal consistency.

\section{Ethical considerations}

A request document was attached to each questionnaire, stating: 'for research purposes, questionnaires should remain unsigned; return of a completed questionnaire signals your consent to participate and agreement to publication of the results'.

\section{Patient and public involvement}

Key stakeholders (home-visit nurses) were involved in this study as described above. Patients and the general public were not involved.

\section{Statistical analysis}

Two separate factor analyses were performed. Total samples $(n=453)$ were randomly divided into two halves for cross validation: group $1 \quad(n=226)$ for performing exploratory factor analysis and group $2(n=227)$ for performing confirmatory factor analysis. To examine the reliability and validity of the initial 38-item HNS-HSC, we used descriptive statistics. After checking the mean Likert-scale score, SD, missing value frequency, kurtosis and skewness of each item, and ceiling and floor effects $($ mean \pm SD) were confirmed, and item-total correlation (I-T) was calculated $(\gamma<0.30)$. We assumed that the elements of home-visiting nursing who contribute to the positive feelings of spousal caregivers are related, so factor analysis was performed using the least squares method and promax rotation. A factor loading of 0.40 was taken as the cut-off value for item selection. The number of factors was determined by the initial solution, using eigenvalues of $>1.0$ and a scree plot.

The fitness of the model obtained through exploratory factor analysis was subsequently confirmed with confirmatory factor analysis. To determine the fitness of the model, we used the $\chi^{2}$ test, comparative fit index (CFI), root mean square error of approximation (RMSEA), and the TuckerLewis index (TLI). CFI and TLI values of 0.90 and above indicate that the model is acceptable. ${ }^{53}$ Meanwhile, an RMSEA of $<0.05$ is considered to represent a good model fit, $0.05-0.08$ an acceptable fit. ${ }^{54}$ To determine reliability, Cronbach's $\alpha$ coefficient was calculated, with values of 0.7 or more indicating good internal consistency. ${ }^{55}$ In a previous study, ${ }^{56}$ there was no correlation between nurse attitudes towards palliative care and terminal care experience. Therefore, to examine the discriminant validity, it was assumed that there was almost no correlation between the HNS-HSC, which evaluates nursing practice, and FATCOD-B-J, which measures nurses' terminal care attitude. GCBT, GCDB and GCAD are scales used to evaluate the frequency of grief care practiced by visiting nurses for family caregivers. Therefore, convergent validity was verified on the assumption that there was a correlation with the HNS-HSC. To determine this validity, we used the Spearman correlation coefficient because the data did not follow the normal distribution. For all statistical analyses, IBM SPSS Statistics V.21.0 and IBM Amos V.24.0 were used.

\section{RESULTS}

\section{Respondents' characteristics}

From the research request sent to 500 facilities, 604 visiting nurses from 255 facilities consented to participate. We consequently received 529 surveys (response rate: $87.6 \%$ ). After the exclusion of questionnaires with missing scale responses, 453 participants (valid response rate: $85.6 \%$ ) were included in the study sample for further analysis. The attributes of the participants are described in table 1.

\section{Factor analysis and the naming of factors}

For each question item, descriptive statistics, ceiling and floor effects were calculated (table 2). The score distribution of these items is displayed in online supplementary appendix 3. Items showing a ceiling effect were deleted after consulting the histogram. There were no items with an I-T correlation of 0.30 or less (table 2). An exploratory factor analysis was performed on the remaining 30 items.

Four items that had factor loadings of $<0.40$ were deleted, leaving 26 items loaded across five factors as displayed in table 3 . This 26 -item scale was adopted as the final version of the HNS-HSC.

Factor I, 'helping spouses plan their futures', comprised seven items, focusing on assessing the spousal caregiver's physical and mental state after death and how 
Table 2 Item analysis of the initial home nursing scale to help spousal caregivers (initial HNS-HSC) $(n=453)$

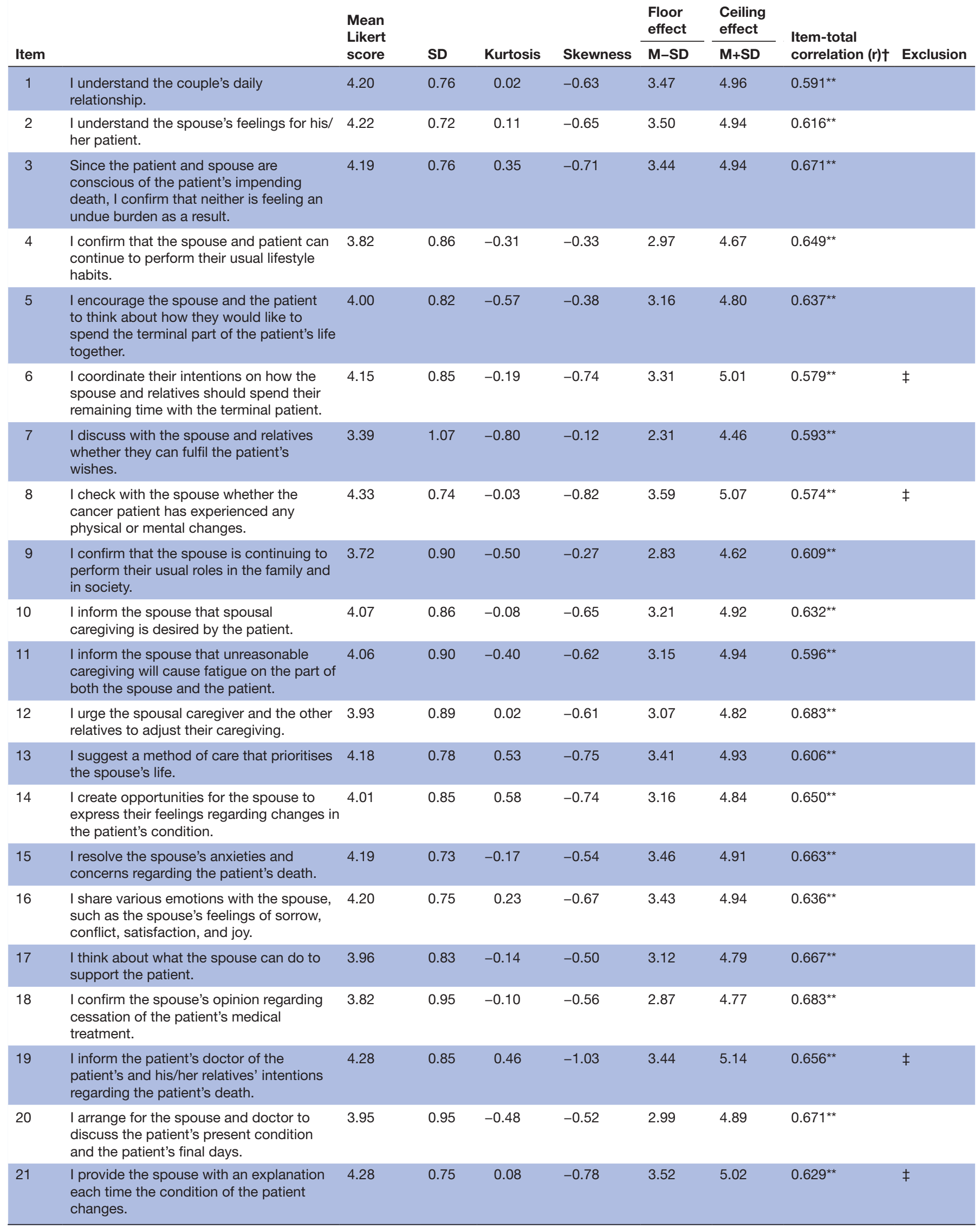

Continued 
Table 2 Continued

\begin{tabular}{|c|c|c|c|c|c|c|c|c|c|}
\hline Item & & $\begin{array}{l}\text { Mean } \\
\text { Likert } \\
\text { score }\end{array}$ & SD & Kurtosis & Skewness & $\begin{array}{l}\begin{array}{l}\text { Floor } \\
\text { effect }\end{array} \\
\text { M-SD }\end{array}$ & $\begin{array}{l}\begin{array}{l}\text { Ceiling } \\
\text { effect }\end{array} \\
\text { M+SD }\end{array}$ & $\begin{array}{l}\text { Item-total } \\
\text { correlation }(r) \dagger\end{array}$ & Exclusion \\
\hline 22 & $\begin{array}{l}\text { I inform the spouse that anticipatory grief } \\
\text { is a natural emotion. }\end{array}$ & 3.89 & 1.02 & -0.24 & -0.67 & 2.86 & 4.90 & $0.696^{\star \star}$ & \\
\hline 23 & $\begin{array}{l}\text { I ensure that the spouse talks about the } \\
\text { patient's death and the postdeath period. }\end{array}$ & 4.06 & 0.90 & 0.60 & -0.89 & 3.17 & 4.94 & $0.664^{\star \star}$ & \\
\hline 24 & $\begin{array}{l}\text { I encourage the spouse to consider things } \\
\text { they can do for the patient up to the point } \\
\text { just before the patient's death. }\end{array}$ & 3.96 & 0.93 & -0.03 & -0.66 & 3.02 & 4.88 & $0.731^{\star \star}$ & \\
\hline 25 & $\begin{array}{l}\text { At patient's death, I advise the spouse and } \\
\text { the relatives to have no regrets regarding } \\
\text { the patient's passing. }\end{array}$ & 4.20 & 0.88 & 0.84 & -1.04 & 3.32 & 5.06 & $0.699^{\star *}$ & $\ddagger$ \\
\hline 26 & $\begin{array}{l}\text { I base the times of my home visits on the } \\
\text { spouse's status during the predeath and } \\
\text { postdeath periods. }\end{array}$ & 3.51 & 1.20 & -0.79 & -0.41 & 2.26 & 4.69 & $0.626^{\star \star}$ & \\
\hline 27 & $\begin{array}{l}\text { I carefully listen to the spouse, so that he/ } \\
\text { she can release his/her emotions. }\end{array}$ & 3.98 & 1.00 & 0.45 & -0.92 & 2.95 & 4.95 & $0.683^{\star *}$ & \\
\hline 28 & $\begin{array}{l}\text { I share memories of the deceased patient } \\
\text { with the spouse. }\end{array}$ & 4.04 & 0.98 & 0.58 & -0.97 & 3.02 & 5.01 & $0.723^{\star \star}$ & $\ddagger$ \\
\hline 29 & $\begin{array}{l}\text { I listen to the spouse's thoughts regarding } \\
\text { caregiving for terminal cancer patients. }\end{array}$ & 4.13 & 0.94 & 1.17 & -1.13 & 3.16 & 5.05 & $0.745^{\star \star}$ & $\ddagger$ \\
\hline 30 & $\begin{array}{l}\text { I commend the spouse for helping the } \\
\text { deceased patient die as he/she wished. }\end{array}$ & 4.26 & 0.91 & 1.95 & -1.40 & 3.34 & 5.16 & $0.705^{\star \star}$ & $\ddagger$ \\
\hline 31 & I help the spouse evaluate their emotions. & 3.72 & 1.01 & -0.18 & -0.59 & 2.69 & 4.71 & $0.752^{\star *}$ & \\
\hline 32 & $\begin{array}{l}\text { I confirm that the spouse maintains a } \\
\text { connection with relatives who were with } \\
\text { the spouse during the patient's terminal } \\
\text { days. }\end{array}$ & 3.36 & 1.13 & -0.57 & -0.35 & 2.22 & 4.47 & $0.737^{\star \star}$ & \\
\hline 33 & $\begin{array}{l}\text { I confirm that the spouse continues to } \\
\text { interact with his/her community. }\end{array}$ & 3.28 & 1.09 & -0.54 & -0.23 & 2.17 & 4.35 & $0.709^{\star *}$ & \\
\hline 34 & $\begin{array}{l}\text { I provide information on social resources, } \\
\text { such as grief-support groups, if necessary. }\end{array}$ & 2.47 & 1.13 & -0.51 & 0.44 & 1.31 & 3.56 & $0.478^{\star \star}$ & \\
\hline 35 & $\begin{array}{l}\text { I confirm the mental and physical status of } \\
\text { the spouse during the grief process. }\end{array}$ & 3.28 & 1.12 & -0.68 & -0.21 & 2.14 & 4.39 & $0.681^{\star *}$ & \\
\hline 36 & $\begin{array}{l}\text { I explain to the spouse the general mental } \\
\text { and physical reactions that occur during } \\
\text { the grieving process. }\end{array}$ & 3.01 & 1.15 & -0.80 & 0.00 & 1.85 & 4.14 & $0.692^{\star *}$ & \\
\hline 37 & $\begin{array}{l}\text { I check the spouse's perception of life } \\
\text { after the patient's death. }\end{array}$ & 3.06 & 1.10 & -0.70 & -0.02 & 1.94 & 4.16 & $0.675^{\star *}$ & \\
\hline 38 & $\begin{array}{l}\text { I assess the necessity of continuing } \\
\text { support. }\end{array}$ & 2.86 & 1.21 & -0.87 & 0.15 & 1.63 & 4.07 & $0.599^{\star \star}$ & \\
\hline
\end{tabular}

Mean Likert-scale scores range from $1=$ 'I do not practice at all’ to $5=$ 'I definitely practice'.

${ }^{\star *} \mathrm{p}<0.01$.

†Correlation coefficient between the item and the total score of all the items (but with exception of the item): less than 0.3 .

¥Ceiling effect were excluded.

HNS-HSC, Home Nursing Scale to Help Spousal Caregivers

likely the caregiver is to proceed with his/her own life after the patient's death. Factor II, 'helping caregivers alleviate any regrets regarding their care', comprised nine items regarding both physical and mental support for spousal caregivers, which encourage spouses and patients to spend their final days satisfactorily. Factor III, 'understanding the bond between a couple', comprised four items, each concerned with ensuring that the couple could spend valuable time together as married partners (rather than as a patient and caregiver) even though the patient is close to death. Factor IV, 'providing support for anticipatory grief', included three items that promote helping the spousal caregiver address any thoughts and fears concerning the imminent death of the patient. Finally, factor V, 'addressing the spousal caregiver's emotions after their spouse's death', included three items that help the spousal caregiver review the care he/she provided and the patient's feelings. Among the factors, II, III and IV concern support before the cancer patient's death, while factors $\mathrm{I}$ and $\mathrm{V}$ concern support after the patient's death. The correlation between these five factors ranged from 0.37 to 0.67 . In addition, the correlations between factors II, III and IV and factors I and V were $0.66(\mathrm{p}<0.01)$. 
Table 3 Factor analysis of the 26 items of the HNS-HSC $n=226$

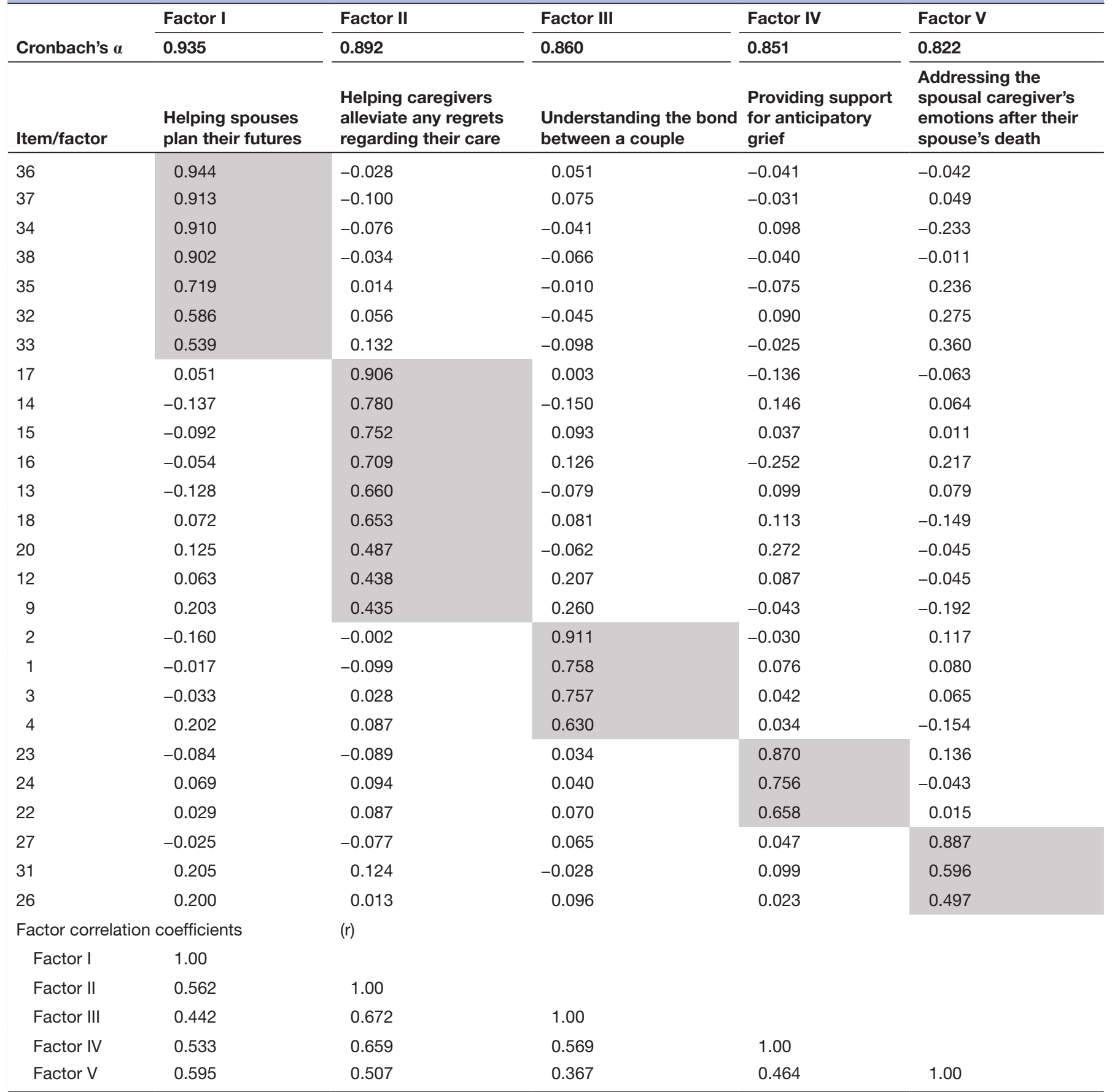

The highlighted values indicate the highest factor loadings for each item. HNS-HSC, Home Nursing Scale to Help Spousal Caregivers.

\section{Confirmatory factor analysis}

Confirmatory factor analysis was used to test the goodness-of-fit of the five factor structures $\left(\chi^{2}=679.628\right.$, $\mathrm{df}=289, \quad \mathrm{CFI}=0.917, \quad \mathrm{TLI}=0.907, \quad \mathrm{RMSEA}=0.077) \quad($ see figure 1). These results indicated that the goodnessof-fit of the 26 -item scale was statistically acceptable.

\section{Reliability}

The Cronbach's $\alpha$ coefficient of the overall HNS-HSC was 0.949 , and it was $0.935,0.892,0.860,0.851,0.822$ for factors I-V, respectively. Thus, the internal consistency was confirmed.

\section{Convergent and discriminant validity}

Regarding the relation between the total scores of the HNS-HSC factors and of FATCOD- B-J, there was a low correlation, between 0.33 and 0.39 for all factors except factor I, which was 0.19 . Regarding the relation between the total scores of the HNS-HSC factors and of the three scales of grief care provided by nurses, we found 


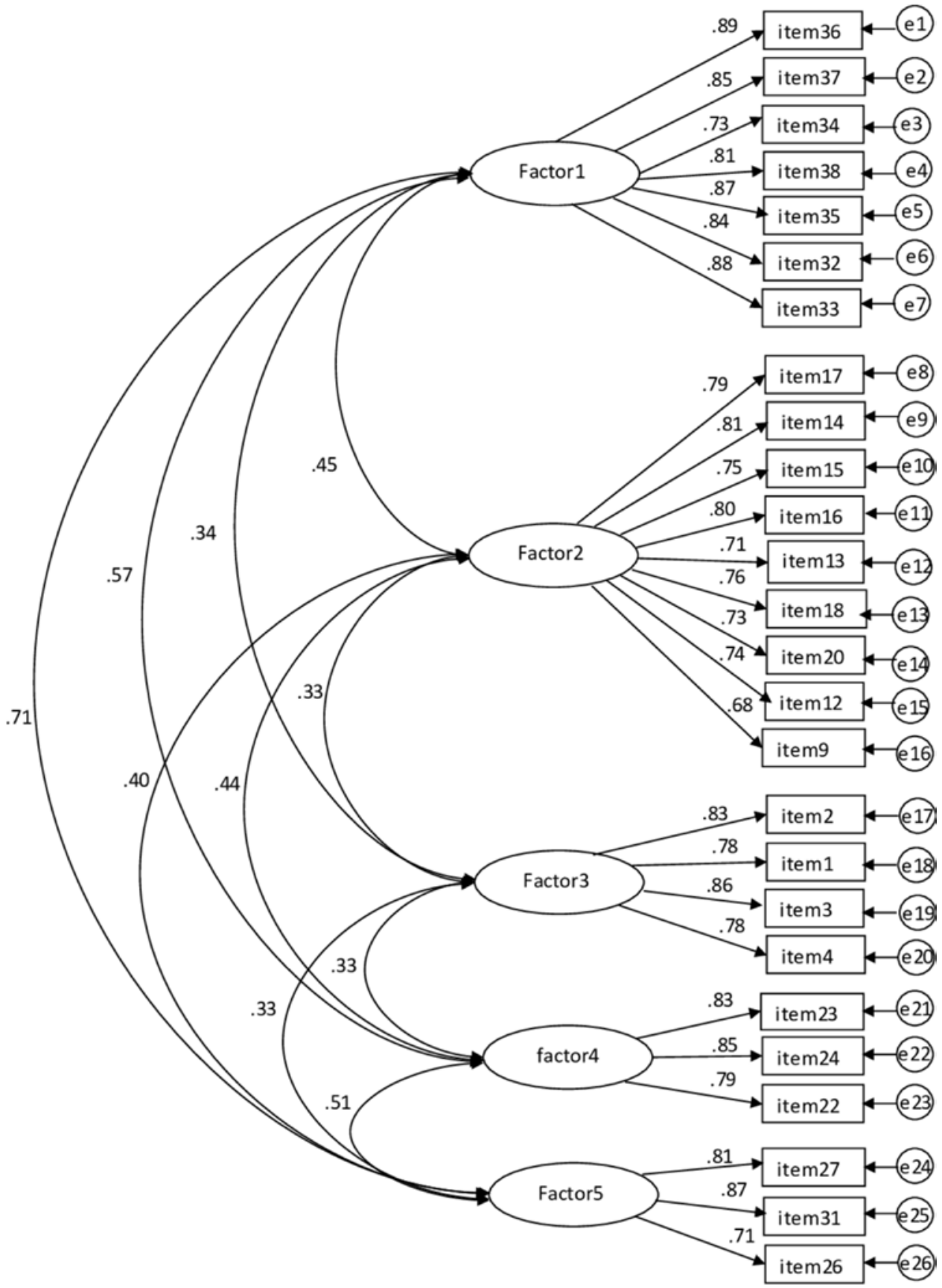

$\chi 2=679.63, \mathrm{CFI}=0.917, \mathrm{TLI}=0.907, \mathrm{RMSEA}=0.077, \mathrm{p}<0.001$

Figure 1 Confirmatory factor analysis for the Home Nursing Scale to Help Spousal Caregivers, showing the Spearman's rank correlation coefficients between each item and factor. Item numbers refer to those of the initial, 38-item scale, e-numbers refer to the new order of the items in the final, 26-item scale. CFI, comparative fit index; RMSEA, root mean square error of approximation; TLI, Tucker-Lewis index.

correlations of $\mathrm{r}=0.64$ for the GCBT, 0.45 for the GCDB and 0.72 for the GCAD (table 4$)$.

\section{DISCUSSION}

In developing the HNS-HSC, we have created a homevisit nursing scale, for use in the periods before and after cancer patient's death to help nurses encourage positive perspectives of caregiving experiences in spousal caregivers. The HNS-HSC scale comprises 26 items across five factors, organised into a consistent timeline from the home-care period to postdeath periods.

\section{How the scale will help caregivers?}

This scale is intended to improve how nurses support spousal cancer caregivers before, during and after the patient's end-of-life care by reinforcing the following five nursing behaviours. 
First, the 'helping spouses plan their futures' domain includes helping spouses to observe their way of life after bereavement with the patient. Confirming how well family caregivers manage after bereavement is an important role in bereavement care. ${ }^{43}$ This domain highlighted the importance of helping spouses to be aware of their own life after the patient's death, which can have a positive impact on the work of grief. Second, the items selected in the 'helping caregivers alleviate any regrets regarding their care' domain included support for the patient's ability to live and hope. This domain highlighted the importance of helping caregivers be satisfied with their spouse's care, which has been shown to lead to a positive understanding of spousal care after bereavement. ${ }^{23}$ It is expected that with the proper nursing support, the spouse will be satisfied with care and can positively assimilate the care experience after bereavement. Third, the items selected in the 'understanding the bond between a couple' domain included support focused on marital relationships. This domain highlighted the importance of encouraging patients and spouses to have a fulfilling end of life in terms of their relationship with each other. In a domestic study, spouses were reassured by 'continuing bonds' that helped them recall memories and have inner conversations with their dead loved ones. ${ }^{57}$ With this support, the couples' ties can be connected from before and after bereavement, and the spouse is less prone to develop complicated grief. Fourth, the "providing support for anticipatory grief' domain includes helping spouses accept the death of patients. Low preparedness for the death of cancer patients' families is associated with complicated grief $^{5859}$ and further depressive symptoms. ${ }^{60}$ This domain emphasises helping spouses share their feelings with nurses and prepare for the patient's death. Fifth, the 'addressing the spousal caregiver's emotions after their spouse's death' domain includes helping the spouse sort out the emotional swings caused by bereavement. It is beneficial for the bereaved family caregivers to review and reflect on the caregiving experience. ${ }^{61}$ This domain stressed the importance of the spouse's mental attitude after bereavement. We believe this domain is an important support for positively understanding the spouse's caregiving experience. Thus, these components should all be essential elements of visiting nurses' approaches in the predeath and postdeath periods to enhance the positive emotions of spousal caregivers of terminal patients.

\section{Examination of convergent and discriminant validity of the HNS-HSC}

Several correlations between the HNS-HSC and existing measures validated evidence of convergent and discriminant validity. As expected, the HNS-HSC scale appeared to correlate with GCBT, GCDB and GCAD. However, when checked by factor, GCDB and factors I and V of the HNS-HSC showed a low correlation. This result seems to be influenced by the fact that GCDB is specialised support for the patient's near-death period, and is not directly related to postdeath support. Moreover, the FAT-COD-B-J and HNS-HSC also showed a low correlation. In particular, there was almost no correlation with factor I of the HNSHSC. Presumably, this result is because the support for a future life and the nurse's thoughts and feelings about terminal care are different structural concepts. Thus, it seems that the assumption that almost no correlation would be found between the HNS-HSC and FAT-COD-B-J, and correlations between GCBT, GCDB, GCAD and HNSHSC would be found is confirmed, supporting the validity of convergent/discriminant of the scale.

\section{Practical implications}

Utilising the HNS-HSC is expected to promote the support that nurses lack in their own practice, increase these customs and raise awareness. Unmet needs of family caregivers such as caregiving and family/social support $^{56263}$ have been shown to be related to their psychological morbidity. ${ }^{5}$ The HNS-HSC focuses on

Table 4 Convergent and discriminant validity of the HNS-HSC

HNS-HSC 
multiple aspects, and it is expected that the use of this scale will strengthen the fulfilment of spouses' needs predeath and postdeath and improve their quality of life. Additionally, the HNS-HSC is expected to serve as an inventory of training needs for nurses. Further, the HNS-HSC will allow visiting nurses who are not confident in home palliative care to reduce the difficulty of care and practice with confidence. Furthermore, since nurses have limited time in their home visits, we believe that the HNS-HSC can be partially used to improve nursing support that is determined to be insufficient for spouses.

\section{LIMITATIONS AND FUTURE ISSUES}

This study has several limitations. First, the questionnaire collection rate for this study was approximately $35 \%$. This result was slightly lower than a cross-sectional mail survey of domestic visiting nurses. Low response rates can cause bias in survey results, so it is necessary to test the no response effect to maximise the validity of future research. Second, the study selected items based on interviews with a limited number of survivors and literature reviews. However, relationships and communication styles between families are different, so it is not possible to assume that all spouses of cancer patients are represented by the selected items. Third, about $41 \%$ of participants in this study had less than 5 years of visiting nurse experience (table 1). Similarly, to Nonogaki et al study, ${ }^{64}$ almost a half of the participants in this study had less than 5 years of vising nurse experience, which may be related to the rapid increase in the number of visiting nurses ${ }^{65}$ that has accompanied Japan's remarkable ageing rate. Further, the percentage of male participants in this study was $3.8 \%$ (table 1), similar to studies of Japanese visiting nurses. ${ }^{2964}$ These numbers are influenced by the Japanese social/ cultural background. Therefore, confirming the HNSHSC's usefulness in other countries in the future will be useful for international discussions. Fourth, item analysis showed lower average values for items 34 and 38 than other items (table 2). This study found that many participants visited the bereaved family's home once within 6 months after bereavement (table 1). However, the appearance of general grief symptoms peaks for 6 months after bereavement. ${ }^{35}$ Therefore, we speculate that there is a limit to the social and continuous nursing practice that can be accomplished during one visit during this period; thus, we believe that the average score of these two items is low. Fifth, as a result of the item analysis of this study, many items with high average scores were found. Previous study has shown that nurse learning opportunities and motivation have improved nursing practice skills. ${ }^{66}$ We surmise that the participants in this study achieved high HNS-HSC scores because over $80 \%$ of the participants already had experience of home palliative care learning and motivation (table 1).

\section{CONCLUSION}

The HNS-HSC has 26 items with five domains. The scale was shown to have reliability and relevance, suggesting that the HNS-HSC may be significant in improving the practical ability of visiting nurses. Additionally, it may have a positive impact on the grieving process of a spouse who cares for a terminal cancer patient at home.

Acknowledgements The authors would like to thank all the participants of our research and interviews. The authors would also like to thank lecturer M Oeki for providing valuable advice throughout the research process.

Contributors MK and HN contributed to the development of the concept and design of this research. HN was responsible for obtaining the approval of the ethics review committee. MK oversaw data collection and analysis, and was in charge of writing a draft of the manuscript. HN supervised the research and manuscript modification. All authors have read and approved the final manuscript.

Funding This research was supported by the Research Assistance fund of the Home Care Association of Japan (grant number 17-004).

Competing interests None declared.

Patient consent for publication Not required.

Ethics approval This study was approved by the Ethical Committee for Epidemiology of Hiroshima University (E-1127). All participants provided their written informed consent. To ensure participant anonymity, the questionnaire contained no identifying details.

Provenance and peer review Not commissioned; externally peer reviewed.

Data sharing statement № additional data are available.

Open access This is an open access article distributed in accordance with the Creative Commons Attribution Non Commercial (CC BY-NC 4.0) license, which permits others to distribute, remix, adapt, build upon this work non-commercially, and license their derivative works on different terms, provided the original work is properly cited, appropriate credit is given, any changes made indicated, and the use is non-commercial. See: http://creativecommons.org/licenses/by-nc/4.0/.

ORCID iD

Mari Karikawa http://orcid.org/0000-0003-0636-3868

\section{REFERENCES}

1 Ministry of Health, Labour and Welfare. Cancer registry and statistics. Tokyo: Cancer Information Service, National Cancer Center, 2017. https://ganjoho.jp/reg_stat/statistics/dl/index.html

2 Ministry of health, labour and welfare, 2018. Available: https://www. mhlw.go.jp/toukei/list/dl/saisyuiryo_a_h29.pdf [Accessed 19 Jul 2019].

3 Ministry of health, labour and welfare, 2016. Available: http//www. mhlw.go.jp/stf/seisakunitsuite/bunya/ 0000106421.html [Accessed 30 Mar 2017].

4 Ministry of health, labour and welfare, 2017. Available: http://www. mhlw.go.jp/toukei/list/81-1.html [Accessed 29 Jan 2019].

5 Areia NP, Fonseca G, Major S, et al. Psychological morbidity in family caregivers of people living with terminal cancer: prevalence and predictors. Pall Supp Care 2019;17:286-93.

6 Kobayakawa M, Ogawa A, Konno M, et al. Psychological and psychiatric symptoms of terminally ill patients with cancer and their family caregivers in the home-care setting: a nation-wide survey from the perspective of bereaved family members in Japan. $J$ Psychosom Res 2017;103:127-32.

7 Butler LD, Field NP, Busch AL, et al. Anticipating loss and other temporal stressors predict traumatic stress symptoms among partners of metastatic/recurrent breast cancer patients. Psychooncology 2005;14:492-502.

8 Nanni MG, Biancosino B, Grassi L. Pre-loss symptoms related to risk of complicated grief in caregivers of terminally ill cancer patients. $J$ Affect Disord 2014;160:87-91.

9 Thomas K, Hudson P, Trauer T, et al. Risk factors for developing prolonged grief during bereavement in family carers of cancer patients in palliative care: a longitudinal study. J Pain Symptom Manage 2014;47:531-41.

10 Jessica YA, William EH. Brent J. S RON S. S, and Susan C. M. bereavement among hospice caregivers of cancer patients one year 
following loss: predictors of grief, complicated grief, and symptoms of depression. J Palliat Med 2013;16:745-51.

11 Götze H, Brähler E, Gansera L, et al. Anxiety, depression and quality of life in family caregivers of palliative cancer patients during home care and after the patient's death. Eur J Cancer Care 2018;27:1 $-8$.

12 Ling S-F, Chen M-L, Li C-Y, et al. Trajectory and influencing factors of depressive symptoms in family caregivers before and after the death of terminally ill patients with cancer. Oncol Nurs Forum 2013;40:E32-40.

13 Field NP, Gal-Oz E, Bonanno GA. Continuing bonds and adjustment at 5 years after the death of a spouse. $J$ Consult Clin Psychol 2003;71:110-7.

14 Lalande KM, Bonanno GA. Culture and continuing bonds: a prospective comparison of bereavement in the United States and the people's Republic of China. Death Stud 2006;30:303-24.

15 Currier JM, Holland JM, Neimeyer RA. Sense-Making, grief, and the experience of violent loss: toward a mediational model. Death Stud 2006;30:403-28.

16 Neimeyer RA, Baldwin SA, Gillies J. Continuing bonds and reconstructing meaning: mitigating complications in bereavement. Death Stud 2006;30:715-38.

17 Stroebe M, Stroebe W, Schut $\mathrm{H}$, et al. Does disclosure of emotions facilitate recovery from bereavement? Evidence from two prospective studies. J Consult Clin Psychol 2002;70:169-78.

18 Klass D, Goss R. Spiritual bonds to the dead in cross-cultural and historical perspective: comparative religion and modern grief. Death Stud 1999;23:547-67.

19 Hudson P. Positive aspects and challenges associated with caring for a dying relative at home. Int $J$ Palliat Nurs 2004;10:58-65.

20 Cohen CA, Colantonio A, Vernich L. Positive aspects of caregiving: rounding out the caregiver experience. Int J Geriatr Psychiatry 2002;17:184-8.

21 Lee GL, Woo IMH, Goh C. Understanding the concept of a "good death" among bereaved family caregivers of cancer patients in Singapore. Pall Supp Care 2013;11:37-46.

22 Karikawa M. Study of end-of-life care experiences and the meanings of those experiences as perceived by the spouse after the death of a cancer patient who was cared for at home. Fam Nurs Res 2017;23:39-51.

23 Wong WKT, Ussher J. Bereaved informal cancer carers making sense of their palliative care experiences at home. Health Soc Care Community 2009;17:274-82.

24 Wong WKT, Ussher J, Perz J. Strength through adversity: bereaved cancer carers' accounts of rewards and personal growth from caring Pall Supp Care 2009;7:187-96.

25 Ellington L, Reblin M, Clayton MF, et al. Hospice nurse communication with patients with cancer and their family caregivers. J Palliat Med 2012;15:262-8.

26 Frommelt KHM. The effects of death education on nurses' attitudes toward caring for terminally ill persons and their families. Am J Hosp Palliat Care 1991;8:37-43.

27 Frommelt KHM. Attitudes toward care of the terminally ill: an educational intervention. Am J Hosp Palliat Care 2003;20:13-22.

28 Yamagishi A, Morita T, Miyashita M, et al. Palliative care in Japan: current status and a nationwide challenge to improve palliative care by the cancer control act and the outreach palliative care trial of integrated regional model (OPTIM) study. Am J Hosp Palliat Care 2008;25:412-8

29 Ono W. Relationships among actions, antecedents, and outcomes of grief care for bereaved caregivers: surveying visiting nurses throughout Japan. Jpn J Nurs Sci 2013;10:212-22.

30 Thomas K, Hudson P, Oldham L, et al. Meeting the needs of family carers: an evaluation of three home-based palliative care services in Australia. Palliat Med 2010;24:183-91.

31 Shimizu M, Nishimura M, Ishii $Y$, et al. Development and validation of scales for attitudes, self-reported practices, difficulties and knowledge among home care nurses providing palliative care. Eur $J$ Oncol Nurs 2016;22:8-22.

32 Sato $\mathrm{K}$, Inoue $\mathrm{Y}$, Umeda M, et al. A Japanese region-wide survey of the knowledge, difficulties and self-reported palliative care practices among nurses. Jpn J Clin Oncol 2014;44:718-28.

33 Matsushima T, Akabayashi A, Nishitateno K. The current status of bereavement follow-up in hospice and palliative care in Japan. Palliat Med 2002;16:151-8.

34 Schwarzer R, Hallum S. Perceived teacher self-efficacy as a predictor of job stress and burnout: mediation analyses. App Psychol 2008;57:152-71.

35 Maciejewski PK, Zhang B, Block SD, et al. An empirical examination of the stage theory of grief. JAMA 2007;297:716-23.
36 Mistry B, Bainbridge D, Bryant D, et al. What matters most for endof-life care? perspectives from community-based palliative care providers and administrators. BMJ Open 2015;5:e007492.

37 Asai M, Akizuki N, Fujimori M, et al. Psychological states and coping strategies after bereavement among spouses of cancer patients: a quantitative study in Japan. Support Care Cancer 2012;20:3189-203.

38 Beckstrand RL, Moore J, Callister L, et al. Oncology nurses perceptions of obstacles and supportive behaviors at the end of life. Oncol Nurs Forum 2009;36:446-53.

39 Jack BA, Baldry CR, Groves KE, et al. Supporting home care for the dying: an evaluation of healthcare professionals' perspectives of an individually tailored hospice at home service. J Clin Nurs 2013;22:2778-86.

40 Jack BA, Mitchell TK, Cope LC, et al. Supporting older people with cancer and life-limiting conditions dying at home: a qualitative study of patient and family caregiver experiences of hospice at home care. $J$ Adv Nurs 2016;72:2162-72.

41 Jo S, Brazil K, Lohfeld L, et al. Caregiving at the end of life: perspectives from spousal caregivers and care recipients. Pall Supp Care 2007:5:11-17.

42 McLeod DL, Tapp DM, Moules NJ, et al. Knowing the family: interpretations of family nursing in oncology and palliative care. Eur $J$ Oncol Nurs 2010;14:93-100.

43 Redshaw S, Harrison K, Johnson A, et al. Community nurses perceptions of providing bereavement care. Int $J$ Nurs Pract 2013:19:344-50.

44 Rhodes RL, Mitchell SL, Miller SC, et al. Bereaved family members' evaluation of hospice care: what factors influence overall satisfaction with services? J Pain Symptom Manage 2008;35:365-71.

45 Bereavement Services Association and National End of Life Care Programme. When a person dies: guidance for professionals on developing bereavement services, 2011. Available: http://bsauk.org/ uploads/834766631.pdf [Accessed 20 Jul 2017].

46 University of Nottingham. Bereavement care services: a synthesis of the literature, 2010. Available: https://www.gov.uk/government/ publications/bereavement-care-services-a-synthesis-of-the-literature [Accessed 20 Jul 2017].

47 Nunnally JC. Psychometric theory. 2nd edn. New York: McGraw-Hill, 1978.

48 Watson R, Thompson DR. Use of factor analysis in Journal of advanced nursing: literature review. J Adv Nurs 2006;55:330-41.

49 Igarashi A, Kurinobu T, Ko A, et al. Factors related to the provision of home-based end-of-life care among home-care nursing, home help, and care management agencies in Japan. BMC Res Notes 2015;8:1-9.

50 Hirooka K, Miyashita M, Morita T, et al. Regional medical professionals' confidence in providing palliative care, associated difficulties and availability of specialized palliative care services in Japan. Jpn J Clin Oncol 2014;44:249-56.

51 Nakai Y, Miyashita M, Sasahara T, et al. Factor Structure and Reliability of the Japanese Version of the Frommelt Attitudes Toward Care of the Dying Scale(FATCOD-B-J). Jpn J Cancer Nurs 2006;11:723-9.

52 Pallant J. SPSS survival manual: a step by step guide to data analysis using SPSS. 4th edn. Maidenhead: McGraw-Hill Education, 2010.

53 Byrne B. Structural equation modeling with AMOS: basic concepts, applications, and programming. London: Routledge, 2010.

$54 \mathrm{Hu}$ Li-tze, Bentler PM. Cutoff criteria for fit indexes in covariance structure analysis: conventional criteria versus new alternatives. Struct Equ Modeling A Multi J 1999;6:1-55.

55 Schneider Z, Elliott D, LoBindo-Wood G, et al. Nursing research: methods, critical appraisal and utilization. 2nd ed. Marrickville: Mosby, 2003.

56 Kassa H, Murugan R, Zewdu F, et al. Assessment of knowledge, attitude and practice and associated factors towards palliative care among nurses working in selected hospitals, Addis Ababa, Ethiopia. BMC Palliat Care 2014:13:1-11.

57 Asai M, Fujimori M, Akizuki N, et al. Psychological states and coping strategies after bereavement among the spouses of cancer patients: a qualitative study. Psychooncology 2010;19:38-45.

58 Schulz R, Boerner K, Klinger J, et al. Preparedness for death and adjustment to bereavement among caregivers of recently placed nursing home residents. J Palliat Med 2015;18:127-33.

59 Tsai W-I, Prigerson HG, Li C-Y, et al. Longitudinal changes and predictors of prolonged grief for bereaved family caregivers over the first 2 years after the terminally ill cancer patient's death. Palliat Med 2016;30:495-503.

60 Hebert RS, Dang Q, Schulz R. Preparedness for the death of a Loved one and mental health in bereaved caregivers of patients with dementia: findings from the reach study. J Palliat Med 2006;9:683-93. 
61 Miyashita M, Aoyama M, Yoshida S, et al. The distress and benefit to bereaved family members of participating in a post-bereavement survey. Jpn J Clin Oncol 2018;48:135-43.

$62 \mathrm{Yi} \mathrm{M}, \mathrm{Kim} \mathrm{H}$. Unmet needs and quality of life of family caregivers of cancer patients in South Korea. Asia Pac J Oncol Nurs 2015;2:152-9.

63 Joad ASK, Mayamol TR, Chaturvedi M. What does the informal caregiver of a terminally ill cancer patient need? A study from a cancer centre. Indian J Palliat Care 2011;17:191-6.
64 Nonogaki A, Nishida T, Kobayashi K, et al. Factors associated with patient information sharing among home-visiting nurses in Japan: a cross-sectional study. BMC Health Serv Res 2019;19:1-10.

65 Ministry of health, labour and welfare. Available: https://www. e-stat.go.jp/stat-search/files?page $=1 \&$ toukei $=00450042 \&$ tstat $=$ 000001029805 [Accessed 2 Aug 2019].

66 Khomeiran RT, Yekta ZP, Kiger AM, et al. Professional competence: factors described by nurses as influencing their development. Int Nurs Rev 2006;53:66-72. 